\title{
Relationship between Social Context and L2 Learning of EFL Students in Tertiary Level
}

\author{
Silvia Morales ${ }^{1}$ \\ ${ }^{1}$ Language Center CENID, Universidad Técnica de Babahoyo, Babahoyo, Ecuador \\ Correspondence: Silvia Morales, Language Center CENID, Universidad Técnica de Babahoyo, Babahoyo, \\ Ecuador. E-mail: smorejon@utb.edu.ec
}

\author{
Received: August 20, 2017 Accepted: September 8, 2017 Online Published: September 11, 2017 \\ doi: 10.5539/elt.v10n10p87 URL: http://doi.org/10.5539/elt.v10n10p87
}

\begin{abstract}
This research analyzed the influence of socioeconomic variables in the L2 learning in beginner students of level one in a language center in a public university in Babahoyo. In addition, variables such as parents' level of education and home environment are analyzed in order to determine the relationship between these variables with L2 learning. Regarding the results, socioeconomic status affects pronunciation of students. Moreover, the influence of the critical period of hypothesis tends to be reduced in L2 learners if the kind of teaching procedure is appropriate to their needs.
\end{abstract}

Keywords: socioeconomic status, level of education; home environment, L2 language learning

\section{Introduction}

Although there is a strong relationship between language and society, it is still complex the direction of its incidence; in other words, if changes in language can produce modifications in society or vice versa. Regarding to this relationship, Wardhaugh (2006) stated that social structure determines linguistic and behavior, which is opposite to the Whorfian and Chomsky hypothesizes. The former claims that linguistic and behavior determine social structure and the ladder stated that there is no relationship between language and society.

In spite of contrary arguments related to relationship between society and language, it is observable throughout a variety of researches that social variables tend to influence language and its process of learning. For instance, Labov (2006) demonstrated that social status influence on the lexicon and pronunciation, specifically with (r) sound. Moreover, Kahn-Horwitz, Shimron and Sparks (2006) and Arikan, (2011) demonstrated with two different researches the incidence of socioeconomic status of learners in their second language learning.

Social variables such as economy, social status, educational background, ethnic and religious tend to influence learners' second language acquisition. The incidence of social milieu has been studied by two researchers Mackey and Spolsky. Mackey throughout his scheme of contextual analysis in language teaching demonstrated how social variables interact with language teaching and learning. In addition, Spolsky presented a group of social factors that affect a bilingual education (Stern, 2003). Hence, social context where learners grow up "exercise a powerful influence in their language learning" (Stern, 2003, p. 269).

Due to the fact that a variety of EFL learners of the language center of the Universidad Técnica de Babahoyo are from different social locations in Babahoyo, such as: downtown, outskirts and countryside; and others are from provinces such as Pichincha, Guayas, La Peninsula, and Bolívar. In addition to their different provenances, they have also demonstrated clear differences in their social backgrounds and it is noticeable the variability of their prior knowledge of English. Therefore, this study intends to identify and understand the connections between social factors related to students' provenance and home environment with their learning of L2.

Referring to Spolsky and his schema about factors that affect L2 learning and Mackey's analysis about relationship between home, area, nation and education. This study will focus only on socioeconomic variable from Spolksy' study and home environment from Mackey's research to study their connection with L2 learning in beginners students. Consequently, this research intends to answer the following questions:

- How socioeconomic status influences students' learning of L2 in EFL context?

- In what ways levels of education of parents have affected students' learning of English? 
- In what ways home environment support students' process of learning English?

\section{Literature Review}

The Socio Cultural Theory (SCT) developed by Vygostky generated a change in people's perception about social context and its incidence in human beings' cognition. The SCT led to multiple analysis and consideration about the role of social and historical context in the field of education, specifically in the L2 learning. Vygostky claimed that social context produced two effects important effects in people's cognition: creation and modification. He maintained that people are social beings, therefore they need to interrelate with others and their environment, this situation makes them to develop and modify symbolic artifacts to facilitate the communication and development of social, economical and cultural relationships (Lantolf, Thorne, \& Poehner, 2015). Therefore, social context provide the psychological space and cognitive tools to generate a variety of relationships throughout a process of regulation based on a collective consciousness of reality.

Society and its social variables such as religious, culture, identity, ethnic, economic power, and social status also influence the point of view about the education and more specifically the perception about learning a second language. Lightbown and Spada (2011) stated that due to the fact that language is used in social context and is developed by social interactions, "it is reasonable that societal factors" affects its and the process to teach and learn it (p. 65).

Moreover, socioeconomic dynamic inside community produces power relations which lead to stratification of social classes and its level of education. Bourdieu (as cited in Wardhaugh, 2006) stated that due to the fact that some languages have received a "symbolic power", because of the economical power that represent, it has led to differentiation between the monolingual and bilingual users, basically in their socioeconomic and academic status (p. 6).

Social context exerts a marked incidence in the language learning and teaching of L2. According to Stern (2003), social context is compounded by a group of social or environmental factors, which exercise a powerful influence in the process of language learning. Those factors are in relation to the society perception about the importance of L2 and L1 in relation to their social class position such as: "social status of L1 and L2, the value of L2, and cultural values related to L1 and L2" (p. 269).

Stern (2003) also argued that social context affects second language learning throughout two directions called opportunities. First, socioeconomic context determines the opportunity to keep in contact with L2, it is done throughout trips to native countries, cable TV, internet and others devices; and the second one represents the opportunities for learning the L2 in an instructional environment, which depends on the quality of materials, equipment, buildings and teachers 'qualification. The opportunities mentioned before are directly influenced by economic and social status, where people with more economical power have more access to L2 contact than low income students.

\subsection{Mackeys' Typology of Bilingual Education}

Mackey (as cited in Stern, 2003) demonstrated how social variables can affect the language learning of L2 in a bilingual environment. He developed nine sceneries, where each one presented a different kind of relationship between nation, area, school and home and their influence in L2 learning. Regarding to the language center of the Universidad Técnica de Babahoyo and its situation with social context, it is observable in typology 4, where the main incidence in L2 acquisition of social context is negative, basically because the L2 is only practiced and spoken in school, while L1 is spoken in the nation, area and at home; hence affecting the opportunities of students to contact with L2 outside classrooms.

\subsection{Spolsky's Representation of Bilingual Education}

Spolsky (as cited by Stern, 2003) presented a schema where he included a group of variables such as psychological, sociological, economic, political, religious-cultural and linguistic, and their incidence in L2 learning. According to Stern (2003), social and cultural factors can define the influence of society in L2 learning. In other words, learners can give importance to L2 acquisition, only if society or a high status social group are interested in L2, hence affecting the students' attitude to L2 learning in linear direction. In regards to economic variables, it is related to the expenses that a social group is determined to invest in L2 education, which obviously depends on their cultural and social perception about the importance of L2 for their socioeconomic and academic status and their economic capacity to afford the expenses.

\section{Methodology and Participants}

Due to the fact that this study attempts to identify and understand sociolinguistic phenomenon from a variety of 
socioeconomic backgrounds that belongs to students from different social status and provenance, it assumes a relativist assumption of the reality, basically because it responds to their own assumptions of their reality. Therefore, their social context is subjective and it is relative to each student (Van Dijk, 2009). Consequently, being congruent with its epistemology background, the research was done throughout an interpretative qualitative study, where students were observed and interviewed to identify the influence of socioeconomic status and their parents' incidence in their L2 learning.

The participants were 18 beginners' students, 16 women and 2 men, they belong to first level in the language center CENID of the Universidad Técnica de Babahoyo and all of them are classmates. They are a mixed group with people from Quito, Babahoyo, Playas, Ricaurte and Mata de Cacao. Their ages are around 19 years old and only one student is 26 years old.

\subsection{Data Collection}

The students attended to a normal class, where the researcher was the English teacher, they reviewed how to introduce themselves, introduce classmate, after that they acted this short dialogue, and then they were introduced to personal information questions. Before the class finished, each group was asked to prepare a video where they had to act the dialogue and include personal questions reviewed in class. Once they got their video they had to send it to the English teacher-researcher mail. Once the researcher got the videos, she studied them and took notes to prepare questions for the interview.

Students were interviewed with their video partners; the interview was done with open questions in the form of an informal conversation in Spanish. The students answered topics related to:

- $\quad$ Place where they live

- The institution where they studied their primary and secondary education

- Their experience learning English in school and high school

- Their parents' job and profession

- Family members who help them with their English learning

- The reason because they make order errors and mispronounce some words in their filmed dialogue

\section{Results of the Data Collection}

\subsection{Videos}

The common error along the six groups was mispronunciation of the words. It was common to observe that they pronounce the English words and alphabet letter following their mother tongue alphabet sound. Moreover, a second problem was related to word order in sentences. Learners tended to make sentences and question following the Spanish structure.

\subsection{Interviews}

Socioeconomic status was measured in function of students' attendance to public and private educative institutions. According to the interview, $72 \%$ of the participants attended to public educative institutions and $28 \%$ were educated in private institutions.

In relation to the age of starting learning English, $44 \%$ of the participants mentioned that they began to learn English in the high school, 50\% started learning L2 in school and 6\% when she started the university. One of the student argued that "when I was at high school, I did not have English classes, it was because I graduated in 2008."

However, many of the students who started learning English since high school argued that they have good teachers. One of them stated that "I finished my primary in a countryside school in Guaranda, we only have a teacher, then when I stated my secondary education I had excellent English teachers, they taught me the verb to be and the simple present, those tenses are helping me now". On the other hand, those students who started learning English since school argued that while some of teachers were good, others did not have a good pedagogy and in some cases were not patient. One of the students from Esmeraldas argued that her primary and secondary education was done in a religious educational institution, where English classes were focused on the alphabet, number and colors, and the amount of hours varied with the different courses, she finally stated that "It was not good the English I learnt in my school and high school". Another student mentioned that her primary English teacher was very good, but when she moved to a public high school, she felt that she could not improve their English knowledge because the teachers repeated the topics that she learnt in her public school. 
Regarding to the level of education of the participants' parents only $16 \%$ finished tertiary level, $22 \%$ secondary level and $61 \%$ concluded primary education. Moreover, when a student was asked about his parents' level of education, he answered that "It is common with me and my classmates, our parents just finished primary education, very few of them secondary ... it is because problems in economic situation, they had to work".

In relation to home environment and L2 learning, only two students have siblings who studied university, it is common that these students help their younger siblings with their English homework and they do not have a family member who can help them with their English tasks. In addition, only one student mentioned that her parents were worried about her acquisition of English, hence they enrolled her in Copei (Copei is a prívate language center, where English is taught) courses, and 17 students stated that their parents are not interested in their English proficiency, they just want them to finish the english modules and their university education, the main reasons that they mentioned refers to the difficult economic situation that they have to face.

\section{Discussion}

Socioeconomic status of learner's have affected their learning of a second language. First of all, due to the fact that parents do not possess enough money to spend in private education, learners had to attend to public schools, where in many cases they did not receive L2 instruction. Hence, many of them started learning English in high school and university. Considering the Critical period hypothesis, it states that there is a moment in child life where they can learn L2 in an "innate form" similar to their mother tongue; it is also believed that this period ends in puberty. Based on Patkowsky' studies (as cited in Lightbown \& Spada, 2011) although adults can learn an L2, the main differences between children and adults L2 learners is observed in their accent and pronunciation. Consequently, due to the fact that students who started learning English in primary had more opportunities to contact with L2, they tend to demonstrated fewer mistakes in pronunciation in their videos than students who started learning English in secondary and tertiary education.

On the other hand, one of the findings in this study refers that although some students started learning English in high school, it is observable a good prior knowledge and few mistakes in pronunciation. Regarding to their answers about the good teachers they had in secondary and their "beliefs and abilities based on their learning experience" to judge the quality of an English lesson (Lightbown \& Spade, 2011, p. 67) it can be assumed that a variable that can help to overcome gaps of English prior knowledge is the teacher's ability to perform well balanced lessons based on the four skills.

Regarding to parents' level of education and its influence in L2 learning, only a parent supports her daughter's learning of English in Copei, but he only finished secondary education. On the other hand, parents who finished primary and tertiary education do not seem to be interested in their sons' and daughters' level of proficiency in English. In addition, both groups of parents do not help learners with their English tasks, basically because they have to work and they do not possess prior knowledge of English. Consequently, these learners do not have a family member who support and help with their tasks and in fact, they are the ones, who help their younger siblings with their English tasks.

\section{Conclusion}

Learners' socioeconomic environment tends to inside in their L2 learning. This relationship have been demonstrated by Burstall (as cited in Lightbown \& Spada, 2011), he found a high correlation between parents 'socioeconomic status and learners' achievement in French. According to his findings, parents with high social economic status motivate their sons to study and facilitated their access to better quality of education. Burstall's findings are observable in the findings of this study, because participants who had access to private education, possess parents who finished secondary and tertiary education, demonstrating through their performance in the video few errors in pronunciation.

In spite of half of the participants started learning english in secondary level, he critical period hypothesis tends to affect only to form of the language not to their comprehension, it is observed throughout the mispronounced words and L1 influence, where although they made errors in pronunciation, students could understand the meaning of the message and interact during the dialogues. In addition, similar results Kahn-Horwitz et al. (2006) found in their research about the effects of L1 and socioeconomic status in reading, they demonstrated that socioeconomic status affected word recognition but not EFL reading comprehension.

Finally, although this research demonstrated that parents with high socioeconomic status tended to be more interested in their sons and daughters education, hence facilitating them the enrolment in private education. It is not clear the common phenomena between parents who only finished primary and some parents who finished secondary and tertiary education, who are not interested in English proficiency, it is noticeable that only one 
parent is worried about it and gave her daughter the opportunity to study english in a private language academy in Guayaquil. It can be comprehensible with low economic status families but this phenomenon includes parents who can afford this expense. Consequently, it is noticeable that more research need to be done in the field of Babahoyo's culture and its society beliefs and perspectives about English learning and its use for professional lives.

\section{References}

Arikan, A. (2010). Prospective English language teachers' perspecptions of the target language and culture in relation to their socioeconomic status. English Language Teaching, 4(3), 232-242.

Bordieu, P. (1991). Language and Symbolic power. Cambridge, Ma: Harvard University Press.

Burstall, C. (1975). French in the primary school: the Britain experiment. Canadian Modern language review, 31(5), 388-402.

Kahn-Horwitz, J., Shimron, J., \& Sparks, R. (2006). Weak and strong readers of English as a foreign language. Annals of Dyslexia, 56(1). 161-185. https://doi.org/10.1007/s11881-006-0007-1

Labov, W. (2006). The social stratification of (r) in New York city department stores. The Social Stratification of English in New York City (pp. 40-56). Cambridge university press.

Lantolf, J., Thorne, S., \& Poehner, M. (2015). Sociocultural theory and second language development. In B. Van Patten, \& J. Williams (Eds.), Theories in second language acquisition (pp. 207-226). New York and London: Routledge Taylor and Francis Group. https://doi.org/10.1017/CBO9780511618208.006

Lightbown, P., \& Spada, N. (2011). Individual differences in second language learning. How Languages are learned (pp. 53-74). New York: Oxford University Press.

Mackey, A. (1999). Input, interaction and second language development: An emprirical study of question formation in ESL. Studies in Srcond Language Acquisition, 21(4), 557-87. https://doi.org/10.1017/S0272263199004027

Patkowski, M. (1980). The sensitive period for the acquisition of syntax in a second language. Language learning, 30(2), 449-472. https://doi.org/10.1111/j.1467-1770.1980.tb00328.x

Stern, H. (2003). The sociology of language teaching and learning. Fundamental concepts of language teaching. (pp. 269-285). New York: Oxford University Press.

Van Dijk, T. (2009). The condition or delimitation of context. Society and discourse: How social context influence text and talk? (pp. 29-85). New York: Cambridge University press. https://doi.org/10.1017/CBO9780511575273

Wardhaugh, R (2006). Introduction. An Introduction to sociolinguistics (pp. 1-22). Cornwall: Blackwell publishing.

\section{Copyrights}

Copyright for this article is retained by the author(s), with first publication rights granted to the journal.

This is an open-access article distributed under the terms and conditions of the Creative Commons Attribution license (http://creativecommons.org/licenses/by/4.0/). 